\title{
Stir bar sorptive-dispersive microextraction by a poly(methacrylic acid-co-ethylene glycol dimethacrylate)-based magnetic sorbent for the determination of tricyclic antidepressants and their main active metabolites in human urine
}

\author{
Víctor Vállez-Gomis ${ }^{1} \cdot$ Sara Exojo-Trujillo ${ }^{1}$. Juan L. Benedé ${ }^{*}$ Alberto Chisvert ${ }^{1}{ }^{\mathbb{D}} \cdot$ Amparo Salvador $^{1}$
}

Received: 8 October 2021 / Accepted: 20 December 2021 / Published online: 8 January 2022

(c) The Author(s) 2022

\begin{abstract}
A poly(methacrylic acid-co-ethylene glycol dimethacrylate)-based magnetic sorbent was used for the rapid and sensitive determination of tricyclic antidepressants and their main active metabolites in human urine. This material was characterized by magnetism measurements, zeta potential, scanning electron microscopy, nitrogen adsorption-desorption isotherms, and thermogravimetric analysis. The proposed analytical method is based on stir bar sorptive-dispersive microextraction (SBSDME) followed by liquid chromatography-tandem mass spectrometry. The main parameters involved in the extraction step were optimized by using the response surface methodology as a multivariate optimization method, whereas a univariate approach was employed to study the desorption parameters. Under the optimized conditions, the proposed method was properly validated showing good linearity (at least up to $50 \mathrm{ng} \mathrm{mL}^{-1}$ ) and enrichment factors (13-22), limits of detection and quantification in the low $\mathrm{ng} \mathrm{L}^{-1}$ range (1.4-7.0 $\mathrm{ng} \mathrm{L}^{-1}$ ), and good intra- and inter-day repeatability (relative standard deviations below 15\%). Matrix effects were observed for the direct analysis of urine samples, but they were negligible when a 1:1 v/v dilution with deionized water was performed. Finally, the method was successfully applied to human urine samples from three volunteers, one of them consuming a prescribed drug for depression that tested positive for clomipramine and its main active metabolite. Quantitative relative recoveries (80-113\%) were obtained by external calibration. The present work expands the applicability of the SBSDME to new analytes and new types of magnetic sorbents.
\end{abstract}

Keywords Active metabolites $\cdot$ Human urine $\cdot$ Magnetic nanoparticles $\cdot$ Polymeric sorbent $\cdot$ Stir bar sorptive-dispersive microextraction · Tricyclic antidepressants

\section{Introduction}

Depression or major depressive disorder is one of the most common chronic or recurrent diseases which negatively affects human feelings, thoughts, and actions. Tricyclic antidepressants (TCAs) are a class of antidepressants traditionally prescribed for the treatment of this disease, but they have been widely replaced by newer drugs. However, either TCAs or some of their active metabolites (i.e., pharmacologically active and chemically stable metabolites

Alberto Chisvert

alberto.chisvert@uv.es

GICAPC Research Group, Department of Analytical Chemistry, University of Valencia, 46100 Burjassot, Valencia, Spain resulting from the biotransformation of the parent drugs) are still prescribed not only for the treatment of depression, but also for other mental health issues [1]. Patients with major depression disorders often suffer overdose as a result of an uncontrolled self-consumption [2], and thus their detection and quantification in biological fluids are mandatory.

Traditionally, conventional liquid-liquid extraction (LLE) [3-5], solid-phase extraction (SPE) [6-8], and dilution/protein precipitation [9-11] are the most common pretreatment procedures applied to the analysis of TCAs in biological samples. However, these methods have many drawbacks such as the consumption of large amounts of sample and organic solvents, time-consuming procedures, and poor selectivity. Recently, microextraction techniques have alleviated these issues and different published methods can be found in the literature for TCAs determination $[12,13]$. 
In general terms, those microextraction techniques based on magnetic (nano)materials, such as magnetic nanoparticles (MNPs) or composite materials made of the combination of MNPs and polymers, have taken on significance due to several reasons [14-16], especially for their easy retrieval by applying an external magnetic field, overcoming the timeconsuming collection and handling of non-magnetic sorbents. In this context, the stir bar sorptive-dispersive microextraction (SBSDME) technique has attracted considerable attention [17]. In this technique, a magnetic (nano)material is added into a vial containing a magnetic neodymium stir bar, so that the magnetic sorbent is attracted by the magnet [18]. At high stirring rate, the magnetic sorbent is dispersed into the sample solution and, once the stirring is halted, the neodymium stir bar rapidly retrieves the sorbent containing the extracted analytes. Finally, when the extraction is completed, the magnetic sorbent-coated stir bar is easily removed from the sample solution and the analytes are desorbed in an adequate solvent (i.e., liquid desorption) or directly thermally desorbed into a gas chromatography (GC) system. The fundamentals of this approach, and an overview of the previously published SBSDME methods, have been recently compiled in a tutorial review [17].

On the other hand, it should be said that polymers, either purposely synthetized or commercially available, have been widely used as sorbents for solid-based microextraction techniques [19-21]. They can be tailored by using a high variety of monomers and, if it is the case, cross-linkers, thus achieving polymers with different properties. Furthermore, they can be tuned with different functional groups for specific purposes according to the extraction requirements [22]. In this respect, polymers made from methacrylic acid (MAA) and ethylene glycol dimethacrylate (EGDMA) as monomer and cross-linker, respectively, i.e., methacrylic acid-co-ethylene glycol dimethacrylate (MAA-co-EGDMA), have been widely used in many different approaches, such as monolith-based microextraction [23, 24], molecularly imprinted polymers-based SPE [25], solid-phase microextraction (SPME) [26, 27], or magnetic dispersive SPE [28]. These types of polymers present a hydrophobic chain structure functionalized with acidic groups, which confers them the capability to establish both hydrophobic and electrostatic interactions $[24,26]$ with basic compounds, such as TCAs. Moreover, if polymers are combined with MNPs, they confer the polymers the needed magnetism to easily handle them with magnetic fields. However, to the best of our knowledge, the combination of these polymers and magnetism has not been greatly exploited.

Thus, the aim of this work is the synthesis of a magnetic MAA-co-EGDMA polymer to be used in SBSDME for the extraction of TCAs. For this purpose, $\mathrm{CoFe}_{2} \mathrm{O}_{4}$ MNPs are chemically coated with $\mathrm{SiO}_{2}$ prior to the anchorage of vinyl moieties by reaction with 3-(trimethoxysilyl)propyl methacrylate (MPS), and the subsequent polymerization of the MAA-co-EGDMA copolymer on them (i.e., $\mathrm{CoFe}_{2} \mathrm{O}_{4} @$ $\mathrm{SiO}_{2} @$ MPS@MAA-co-EGDMA). Different polymerization mixtures, with different monomer:cross-linker molar ratios, were evaluated to obtain the most appropriate and mechanical resistant polymer. The chemistry of this interesting polymer was exploited for the extraction of the five TCAs most usually prescribed and their main active metabolites (Table S1, in Electronic Supplementary Material (ESM)) from urine samples. The main parameters affecting the extraction were carefully optimized through a response surface methodology (RSM), and those affecting the desorption were optimized by a univariate approach. Liquid chromatography-tandem mass spectrometry (LC-MS/MS) was used for analytes identification and quantification.

\section{Experimental}

\section{Reagents}

All reagents and solvents were obtained from major suppliers. Amitriptyline (AMT) hydrochloride $\geq 98 \%$, nortriptyline (NORT) hydrochloride $\geq 98 \%$, imipramine (IMP) hydrochloride $\geq 99 \%$, desipramine (DIMP) hydrochloride $\geq 98 \%$, trimipramine (TMP) maleate $\geq 98 \%$, clomipramine (CMP) hydrochloride $\geq 98 \%$, doxepin (DOX) hydrochloride $\geq 98 \%$, methanolic solution containing $1000 \mu \mathrm{g} \mathrm{mL}^{-1}$ of N-desmethylclomipramine (NCMP) hydrochloride and methanolic solution containing $1000 \mu \mathrm{g} \mathrm{mL} \mathrm{m}^{-1}$ of cis/trans desmethyldoxepin (NDOX) from Sigma-Aldrich (St. Louis, USA, https://www.sigmaaldrich.com), and methanolic solution containing $1000 \mu \mathrm{g} \mathrm{mL} \mathrm{m}^{-1}$ of desmethyltrimipramine (NTMP) hydrochloride from LGC Standards (Luckenwalde, Germany, https://www.lgcstandards.com) were used as standards. Their chemical structures and relevant data are given in Table $\mathrm{S} 1$ (ESM).

For the synthesis of $\mathrm{CoFe}_{2} \mathrm{O}_{4}$ MNPs, cobalt(II) chloride hexahydrate $\left(\mathrm{CoCl}_{2} \cdot 6 \mathrm{H}_{2} \mathrm{O}\right)$ and iron(III) chloride hexahydrate $\left(\mathrm{FeCl}_{3} \cdot 6 \mathrm{H}_{2} \mathrm{O}\right)$ were purchased from Acros Organics (New Jersey, USA, https://www.acros.com), and sodium hydroxide $(\mathrm{NaOH})$ reagent grade was purchased from Scharlau (Barcelona Spain, https://www.scharlau.com).

For the synthesis of the magnetic sorbent, tetraethylorthosilicate (TEOS) 98\%, 3-(trimethoxysilyl) propyl methacrylate (MPS) 98\%, and 2,2'-azobis(2-methylpropionitrile) (AIBN), methacrylic acid (MAA), and ethylene glycol dimethacrylate (EGDMA) from Sigma-Aldrich (Darmstadt, Germany) were used.

For the determination of the creatinine content in the urine samples, creatinine anhydrous $\geq 98 \%$ and picric acid moistened with water $\geq 98 \%$ were purchased from SigmaAldrich (St. Louis, USA). 
HPLC grade absolute ethanol and HPLC grade acetonitrile from PanReac AppliChem (Damstadt, Germany, https:// www.itwreagents.com), reagent grade ammonia and reagent grade hydrochloric acid from Scharlau (Barcelona, Spain), and ultrapure water (resistivity $\geq 18.2 \mathrm{M} \Omega \cdot \mathrm{cm}$ ) obtained through of a Connect purification system from Adrona (Riga, Latvia, http://www.adrona.lv) have been used as solvents for the synthesis process.

Methanol (MeOH) grade LC-MS from VWR Chemicals (Fontenay-sous-Bois, France, https://es.vwr.com/store) has been used for the conditioning of the magnetic sorbent prior to extraction, and analytical grade sodium chloride $(\mathrm{NaCl})$ (99.5\%) from Acros Organics (Geel, Belgium) to adjust the ionic strength of the donor phase. Glacial acetic acid (AcOH) from Scharlau (Barcelona, Spain) has been used for the preparation of the solvent mixture for the liquid desorption.

The chromatographic mobile phase used was methanol grade LC-MS from VWR Chemicals (Fontenay-sous-Bois, France) and water grade LC-MS from Panreac (Barcelona, Spain), both with $0.1 \%$ formic acid LC-MS grade from VWR Chemicals.

Nitrogen, used as nebulizer and curtain gas in the MS/ MS ion source, was obtained by a NiGen LC-MS 40.0 nitrogen generator from Claind S.r.l. (Lenno, Italy, https://www. claind.it/en/home). Extra pure nitrogen (>99.999\%) from Praxair (Madrid, Spain) was used as collision gas in the MS/ MS collision cell.

\section{Samples}

The analyte-free urine samples used for the development and validation of the method were obtained from different healthy volunteers who did not consume any type of antidepressants. In addition, a sample from a volunteer who did consume a prescribed drug containing $25 \mathrm{mg}$ of CMP per tablet was analyzed. The amount ingested by this volunteer was one tablet at breakfast, one tablet at lunch, and two tablets at dinner. Each volunteer gave their written informed consent to participate in this study, which followed the ethical guidelines of the Declaration of Helsinki, and it was approved by the Ethical Committee of the University of Valencia (Spain). All urine samples were collected in sterile plastic containers and kept at $4{ }^{\circ} \mathrm{C}$ in the refrigerator until analysis.

\section{Apparatus and materials}

An Agilent 1100 Series chromatography system comprising a degasser, a quaternary pump, an autosampler, and a thermostatic column oven coupled to an Agilent 6410B Triple Quad MS/MS was employed throughout the study.
A 10-position multiple stirring plate model MS-M-S10 from DLAB Scientific Europe S.A.S (Schiltigheim, France) and $\mathrm{NdFeB}$ magnets $(54 \mathrm{MGO}, 10 \mathrm{~mm}$ length $\times 3 \mathrm{~mm}$ diameter) from Supermagnete (Gottmadingen, Germany) were used for SBSDME.

A ZX3 vortex mixer from VELP Scientifica (Usmate Velate, Italy) and an Ultrasons-HD ultrasonic bath from JP Selecta (Barcelona, Spain) were used in the synthesis stage.

A Jenway 6305 UV/Vis spectrophotometer from ColeParmer Ltd (Staffordshire, UK) was used for the determination of creatinine in urine samples.

A Basic $20 \mathrm{pH}$ meter from Crison (Alella, Spain) was used for the $\mathrm{pH}$ adjustments.

All those instruments used for characterization of the sorbent material are listed in ESM.

\section{Synthesis of $\mathrm{CoFe}_{2} \mathrm{O}_{4} @ \mathrm{SiO}_{2} @ M P S @ M A A-c o-E G D M A$ magnetic sorbent}

The synthesis of the $\mathrm{CoFe}_{2} \mathrm{O}_{4} @ \mathrm{SiO}_{2} @ \mathrm{MPS} @ \mathrm{MAA}-\mathrm{co}-$ EGDMA sorbent consists of two global stages (Fig. 1): (1) the synthesis of the magnetic component, i.e., the $\mathrm{CoFe}_{2} \mathrm{O}_{4}$ MNPs, by chemical coprecipitation according to a modified protocol [29]; and (2) their chemical functionalization with the polymeric component (i.e., MAA-co-EGDMA). The adopted synthesis procedure consisted of a step-by-step process in order to ensure the chemical functionalization of the $\mathrm{CoFe}_{2} \mathrm{O}_{4}$ MNPs with the MAA-co-EGDMA polymer. In this sense, previous coatings with TEOS and then with MPS were needed to confer a $\mathrm{SiO}_{2}$ shell with reactive silanol groups and to provide functional vinyl moieties, respectively. Finally, the co-polymerization of MAA and EGDMA on these vinyl groups using AIBN as radical initiator was performed [30]. The EGDMA confers rigidity to the polymer and the MAA provides acidic functional groups available to interact with the basic analytes to the final sorbent.

Figure 1 schematizes the synthesis procedure of the magnetic sorbent, whereas the experimental details are described in ESM.

\section{Proposed method}

\section{External calibration and sample solutions}

A $500-\mu \mathrm{g} \mathrm{mL}^{-1}$ multicomponent solution of the solid analytes (i.e., DOX, IMP, DIMP, AMT, TMP, NORT, and CMP) was prepared in $\mathrm{MeOH}$. In parallel, from the $1000-\mu \mathrm{g} \mathrm{mL}{ }^{-1}$ solutions of the rest of the analytes (i.e., NDOX, NTMP, and NCMP), individual solutions of $100 \mu \mathrm{gL}^{-1}$ in $\mathrm{MeOH}$ were prepared. From all the previous solutions, an intermediate multicomponent solution was prepared in water containing $5 \mu \mathrm{g} \mathrm{mL}{ }^{-1}$ of all the analytes and, from this, another aqueous solution of $50 \mathrm{ng} \mathrm{mL}^{-1}$ was prepared. These solutions were 


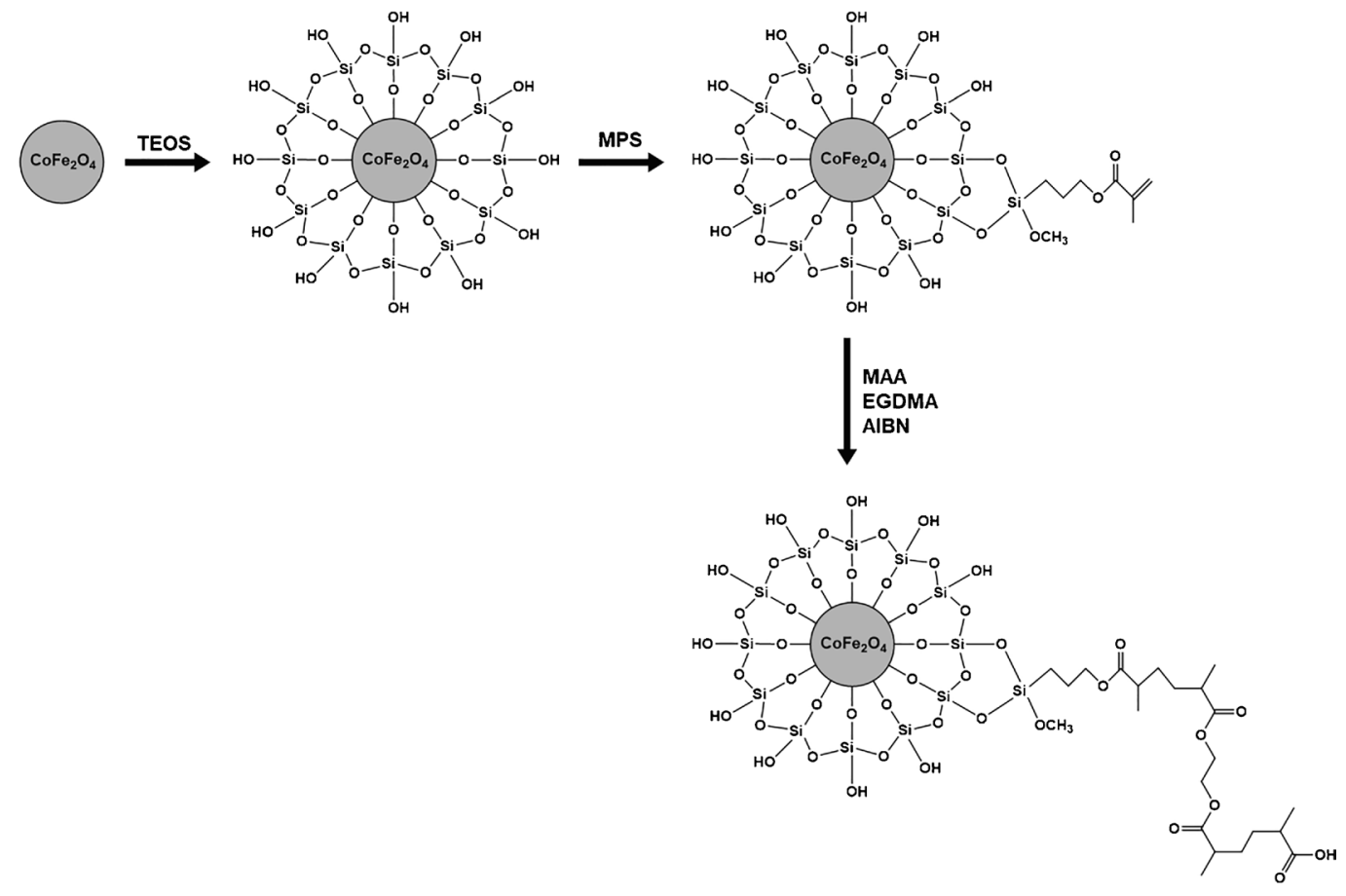

Fig. 1 Synthesis of the $\mathrm{CoFe}_{2} \mathrm{O}_{4} @ \mathrm{SiO}_{2} @$ MPS@MAA-co-EGDMA sorbent

stored at $4{ }^{\circ} \mathrm{C}$ protected from light exposure to avoid possible degradation. From the $50-\mathrm{ng} \mathrm{mL}^{-1}$ solution, working solutions (from 0.1 to $1 \mathrm{ng} \mathrm{mL}^{-1}$ ) were prepared in $6.8 \% \mathrm{w} / \mathrm{v}$ $\mathrm{NaCl}$ aqueous solution.

Prior to analysis, urine samples were conveniently diluted with deionized water, and $\mathrm{NaCl}$ was added to have $6.8 \% \mathrm{w} / \mathrm{v}$ in the measuring solution, thus ensuring that all analytes were at concentrations within the range of the study. In any case, at least $1: 1 \mathrm{v} / \mathrm{v}$ dilution was required to avoid matrix effects (as discussed later).

\section{Stir bar sorptive-dispersive microextraction procedure}

Prior to the extraction step, the $\mathrm{CoFe}_{2} \mathrm{O}_{4} @ \mathrm{SiO}_{2} @ \mathrm{MPS} @$ MAA-co-EGDMA sorbent was conveniently preconditioned. For this purpose, $15 \mathrm{mg}$ of the sorbent was introduced into a clean and dry $40-\mathrm{mL}$ vial and dispersed in $2 \mathrm{~mL}$ of $\mathrm{MeOH}$ with the help of a neodymium stir bar $(10 \mathrm{~mm}$ length $\times 3 \mathrm{~mm}$ diameter) for $2 \mathrm{~min}$. Once the stirring stopped, the magnetic material was strongly attracted to the stir bar. This stir bar coated with the material was removed from the solution with the help of plastic tweezers and placed into a $40-\mathrm{mL}$ extraction vial. Then, $25 \mathrm{~mL}$ of each standard solution or diluted sample were introduced, respectively, to each vial containing the corresponding neodymium stir bar with the preconditioned sorbent. Then, all the vials were stirred by means of a 10-position multiple stirring plate for $5 \mathrm{~min}$ at a high-speed rate to allow the dispersion of the material into each solution at room temperature. After the extraction time elapsed, stirring was stopped and the magnetic material returned to the stir bar. Each sorbent-coated stir bar was then removed with plastic tweezers and placed in a $5-\mathrm{mL}$ desorption vial containing $0.25 \mathrm{~mL}$ of $\mathrm{MeOH}: \mathrm{H}_{2} \mathrm{O}: \mathrm{AcOH}$ 6:3:1 v/v/v, as desorption solvent, to carry out the liquid desorption of the analytes. They were stirred for $5 \mathrm{~min}$, and the extracts were filtered through a $0.22-\mu \mathrm{m}$ nylon filter into injection vials. Finally, the extracts were analyzed by LC-MS/MS. Figure 2 shows a schematic diagram of the SBSDME procedure.

\section{Liquid chromatography-tandem mass spectrometry analysis}

The chromatographic separation was carried out in a Zorbax SB-C18 (50 mm length, $2.1 \mathrm{~mm}$ I.D., $1.8 \mu \mathrm{m}$ ) column. Five microliters of each extract were injected into the chromatographic system. The flow rate was $0.3 \mathrm{~mL} \mathrm{~min}^{-1}$, and the column temperature was kept constant at $35^{\circ} \mathrm{C}$. The mobile phase consisted of solvent $\mathrm{A}\left(\mathrm{H}_{2} \mathrm{O}, 0.1 \% \mathrm{v} / \mathrm{v}\right.$ formic acid $)$ and solvent $\mathrm{B}$ (MeOH, $0.1 \% \mathrm{v} / \mathrm{v}$ formic acid), and the pump supplied the following gradient program: 0 to $1 \mathrm{~min}$, linear gradient from 40 to $60 \%$ solvent $\mathrm{B}$; held for $3.5 \mathrm{~min}$; 4.5 to $4.6 \mathrm{~min}$ return to $40 \%$ solvent B and held for $5.4 \mathrm{~min}$. The run time was $10 \mathrm{~min}$.

The triple quadrupole MS detector operated in positive electrospray ionization mode $\left(\mathrm{ESI}^{+}\right)$, at $3 \mathrm{kV}$, by multiple reaction monitoring (MRM). The flow rate and the 
Fig. 2 Schematic diagram of the experimental procedure

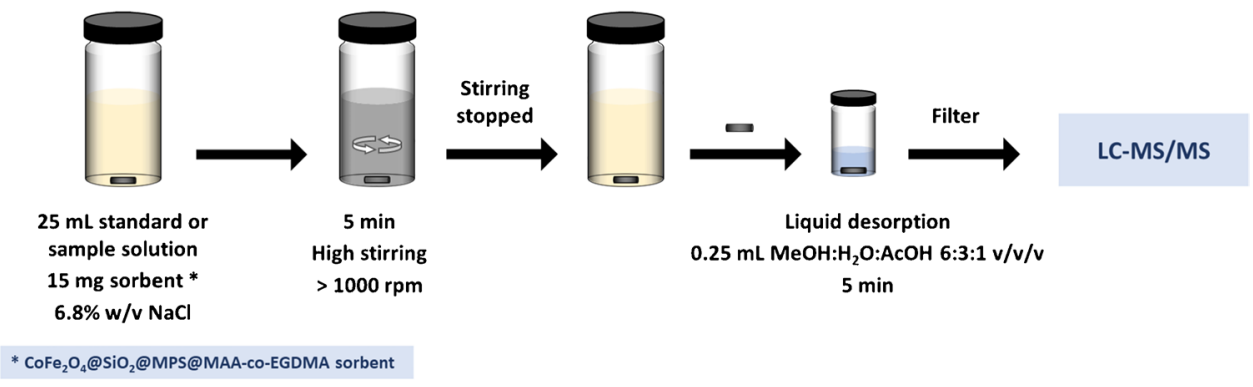

temperature of the drying gas and the nebulizer pressure were $10 \mathrm{~L} \mathrm{~min}^{-1}, 250{ }^{\circ} \mathrm{C}$, and $25 \mathrm{psi}$, respectively. The $\mathrm{m} / \mathrm{z}$ precursor $\rightarrow$ product ion transitions for quantification and for identification and the collision energies and fragmentor values for each analyte are shown in Table S2 (ESM).

Figure S1 (ESM) shows a chromatogram of a standard containing the analytes at $0.5 \mathrm{ng} \mathrm{mL}^{-1}$ obtained after applying the SBSDME-LC-MS/MS approach

\section{Results and discussion}

\section{Selection of the monomer:cross-linker molar ratio}

Results of the selection of the MAA:EGDMA molar ratio are discussed in ESM. Briefly, the 1:4 MAA:EGDMA molar ratio presented the highest extraction for all the target analytes, probably due to its high availability of acidic functional groups to interact with the basic analytes, and its high mechanical resistance. Thus, this sorbent was selected as sorbent for further analysis.

\section{Characterization of the $\mathrm{CoFe}_{2} \mathrm{O}_{4} @ \mathrm{SiO}_{2} @ M P S @$ MAA-co-EGDMA magnetic sorbent}

For the characterization of the selected $\mathrm{CoFe}_{2} \mathrm{O}_{4} @ \mathrm{SiO}_{2} @$ MPS@MAA-co-EGDMA magnetic sorbent, different techniques were used to study properties such as the magnetization $\left(\mathrm{M}_{\mathrm{S}}\right)$, the surface charge, the morphology, the adsorption properties, and the thermal stability. All these results are described in detail in ESM. In summary, the magnetization curve showed a satisfactory value of $\mathrm{M}_{\mathrm{S}}(47.8 \mathrm{emu}$ $\mathrm{g}^{-1}$ ) to carry out the SBSDME procedure. The point of zero charge $\left(\mathrm{pH}_{\mathrm{pzc}}\right)$, i.e., the $\mathrm{pH}$ at which the surface charge was zero, was determined to be ca. 3.3. The scanning electron microscopy (SEM) showed the expected spherical shape of the sorbent due to the successive coating of $\mathrm{CoFe}_{2} \mathrm{O}_{4} \mathrm{MNPs}$ by $\mathrm{SiO}_{2}$, by MPS, and by the MAA-co-EGDMA polymer. The surface area was $60.7 \pm 0.2 \mathrm{~m}^{2} \mathrm{~g}^{-1}$. Finally, the thermogravimetric analysis revealed that the sorbent was stable until $300^{\circ} \mathrm{C}$.

\section{Optimization of the extraction variables}

The factors affecting the extraction procedure were optimized by using the RSM as a multivariate optimization method [31]. To this respect, a four-factor three-level BoxBenhken design was employed. Thus, the sorbent amount $\left(X_{1}\right)$, extraction time $\left(X_{2}\right), \mathrm{pH}\left(X_{3}\right)$, and ionic strength $\left(X_{4}\right)$ were considered as the potential factors affecting the extraction of the analytes, and they were optimized by performing 27 experiments (see ESM). The selected analytical responses were the peak areas of each analyte. StatGraphics Centurion XVI (Stat Point Inc. Herndon, VA, USA) software was employed for the statical analysis. The statistics of the description of the Box-Behnken design is included in ESM (see Table S3).

To this regard, sorbent amount (5-20 mg), extraction time (5-30 $\mathrm{min}$ ), $\mathrm{pH}$ of the donor phase (2-8, adjusted by adding $0.035 \mathrm{~g}$ of $\mathrm{H}_{2} \mathrm{NaPO}_{4} \cdot \mathrm{H}_{2} \mathrm{O}$ to $25 \mathrm{~mL}$ of aqueous solution and either o-phosphoric acid or ammonia), and ionic strength of the donor phase $(0-10 \% \mathrm{NaCl})$ were evaluated. All the experiments were performed using $25 \mathrm{~mL}$ of aqueous standard solution at $5 \mathrm{ng} \mathrm{mL}^{-1}$. The desorption of the target analytes was carried out in $0.5 \mathrm{~mL}$ of $\mathrm{MeOH}: \mathrm{H}_{2} \mathrm{O}: \mathrm{AcOH}$ 6:3:1 $\mathrm{v} / \mathrm{v} / \mathrm{v}$ for $5 \mathrm{~min}$.

Details of the optimization of the extraction variables are described in ESM. In short, according to RSM curves shown in Fig. S9 (ESM), there was no difference between 15 and $20 \mathrm{mg}$ of $\mathrm{CoFe}_{2} \mathrm{O}_{4} @ \mathrm{SiO}_{2} @$ MPS @MAA-co-EGDMA, so $15 \mathrm{mg}$ was selected as the optimum amount of sorbent. An extraction time of $5 \mathrm{~min}$ was enough to quantitatively extract the TCAs, so that it was selected for further experiments. Regarding the $\mathrm{pH}$ of the donor phase, optimum extraction values were observed between 5 and $7 \mathrm{pH}$ values. At this range, an electrostatic interaction between the analytes and the sorbent is given due to the positive charge of the amine group of the TCAs (pKa 9.2-10.4) and the negatively charged surface of the sorbent $\left(\mathrm{pH}_{\mathrm{pzc}} 3.3\right)$. Therefore, it would not be mandatory to be adjusted since the $\mathrm{pH}$ of the diluted urine is nearby 6 . Finally, the optimum ionic strength was achieved at $6.8 \% \mathrm{w} / \mathrm{v} \mathrm{NaCl}$. 


\section{Optimization of the desorption variables}

The desorption conditions were also evaluated, in triplicate, using a univariate approach under the extraction conditions previously optimized. In this regard, the desorption solvent, desorption time, and desorption volume were selected as the variables affecting the desorption of the target analytes. In this case, the selected analytical response was the enrichment factor (EF), defined as $\mathrm{EF}=A_{\text {ext }} / A_{0}$, where $A_{\text {ext }}$ is the peak area of each target analyte after the extraction procedure (i.e., in the final extract), and $A_{0}$ is the initial peak area of this analyte (i.e., in the donor solution before the extraction).

Details of the optimization of the desorption variables are discussed in ESM. Briefly, the best EF values were achieved when $0.25 \mathrm{~mL}$ of $\mathrm{MeOH}: \mathrm{H}_{2} \mathrm{O}: \mathrm{AcOH}$ 6:3:1 v/v/v was used for 5 min during the desorption process (see Figs. S10-S12 (ESM)). This is probably due to the low pH level (ca. 2.2) caused by the $\mathrm{AcOH}$, which leads to an electrostatic repulsion between the positively charged surface of the sorbent $\left(\mathrm{pH}_{\mathrm{pzc}}\right.$ of 3.3) and the positively charged amine groups of the TCAs (pKa 9.2-10.4).

\section{Extraction efficiency of the $\mathrm{CoFe}_{2} \mathrm{O}_{4} @ \mathrm{SiO}_{2} @ M P S @$ MAA-co-EGDMA sorbent}

In order to demonstrate the extraction efficiency of the MAA-co-EGDMA polymer within the synthesized magnetic sorbent, bare $\mathrm{CoFe}_{2} \mathrm{O}_{4}$ MNPs, MAA-co-EGDMA polymer, and $\mathrm{CoFe}_{2} \mathrm{O}_{4} @ \mathrm{SiO}_{2} @$ MPS@MAA-co-EGDMA magnetic polymer were tested as sorbent materials under the optimized extraction and desorption conditions. Since the polymer is not magnetic by itself, its retrieval after extraction was performed by centrifugation for $5 \mathrm{~min}$ at $6000 \mathrm{rpm}$. The extraction efficiency was estimated according to Eq. (1) described in the ESM, and these results are shown in Fig. S13 (ESM). As can be seen, the \% extraction of bare $\mathrm{CoFe}_{2} \mathrm{O}_{4}$ MNPs is minimal when compared to that of the MAA-co-EGDMA polymer. Moreover, the presence of the coated $\mathrm{CoFe}_{2} \mathrm{O}_{4}$ MNPs in the final magnetic sorbent did not affect the extraction efficiency of the MAA-co-EGDMA polymer.

\section{Inter-batch repeatability of the $\mathrm{CoFe}_{2} \mathrm{O}_{4} @ \mathrm{SiO}_{2} @$ MPS@MAA-co-EGDMA sorbent}

The repeatability between different batches of the $\mathrm{CoFe}_{2} \mathrm{O}_{4} @ \mathrm{SiO}_{2} @ \mathrm{MPS} @ \mathrm{MAA}-\mathrm{co}-\mathrm{EGDMA}$ sorbent was also evaluated. For this purpose, three replicates of an aqueous standard solution containing $250 \mathrm{ng} \mathrm{L}^{-1}$ of the analytes were extracted, under the optimized conditions, with three different batches of the sorbent synthesized as described in
“Synthesis of $\mathrm{CoFe}_{2} \mathrm{O}_{4} @ \mathrm{SiO}_{2} @ \mathrm{MPS} @ \mathrm{MAA}-\mathrm{co}-\mathrm{EGDMA}$ magnetic sorbent." As can be seen in Fig. S14 (ESM), similar results were obtained with the three batches, so it can be concluded that the synthesis of the material is repeatable and provides batches with very similar extraction capability.

\section{Study of the matrix effects}

In order to study the matrix effect of the urine samples during the analytical process, the slopes of the calibration plots obtained in water (external calibration) and those obtained using a pool of three free-analyte urine samples (matrixmatched calibration), both subjected to the optimized SBSDME procedure, were compared for a $5 \%$ significance level by applying the Student's $t$-test [32]. The slopes obtained for both calibration methods are shown in Table S4 (ESM). Given that the obtained results suggested negative matrix effects, a dilution of the urine sample was tested in order to avoid matrix effects. In this sense, different dilutions were studied to find out at what dilution the matrix effect was negligible. As can be seen in Fig. S15 (ESM), the matrix effect was negligible when a 1:1 v/v dilution or higher was used. Therefore, an external calibration can be used as long as the urine sample was diluted at least at $1: 1 \mathrm{v} / \mathrm{v}$.

\section{Analytical figures of merit}

Method validation was performed evaluating different parameters, such as linearity, instrumental and method limits of detection (ILOD and MLOD, respectively) and quantification (ILOQ and MLOQ, respectively), EF, and repeatability (expressed as relative standard deviation (RSD)), under the optimized conditions defined above. These parameters are shown in Table 1.

A high level of linearity was accomplished, reaching at least up to $50 \mathrm{ng} \mathrm{mL}^{-1}$, with coefficients of determination $\left(R^{2}\right)>0.997$.

The ILODs and ILOQs were calculated as 3 times and 10 times, respectively, the signal-to-noise ratio. They ranged from 1.4 to $7.0 \mathrm{ng} \mathrm{L}^{-1}$, and from 4.7 to $23.1 \mathrm{ng} \mathrm{L}^{-1}$, respectively. On the other hand, MLODs and MLOQs were obtained considering a 1:1 v/v dilution of the urine sample. Thus, these values ranged from 2.9 to $14.0 \mathrm{ng} \mathrm{L}^{-1}$, and from 9.4 to $46.1 \mathrm{ng} \mathrm{L}^{-1}$, respectively.

The EF values were estimated as mentioned above and taking into account a 1:1 v/v dilution of the urine sample. Hence, the net EFs values ranged from 13 to 22 .

Finally, the precision of the proposed SBSDME method was calculated from the analysis of five independent replicate aqueous standard solutions containing the target analytes at three different concentration levels (i.e., 50, 250, and $1000 \mathrm{n} \mathrm{L} \mathrm{L}^{-1}$ ) in the same day (intra-day repeatability) and in five consecutive days (inter-day repeatability). RSD values, 


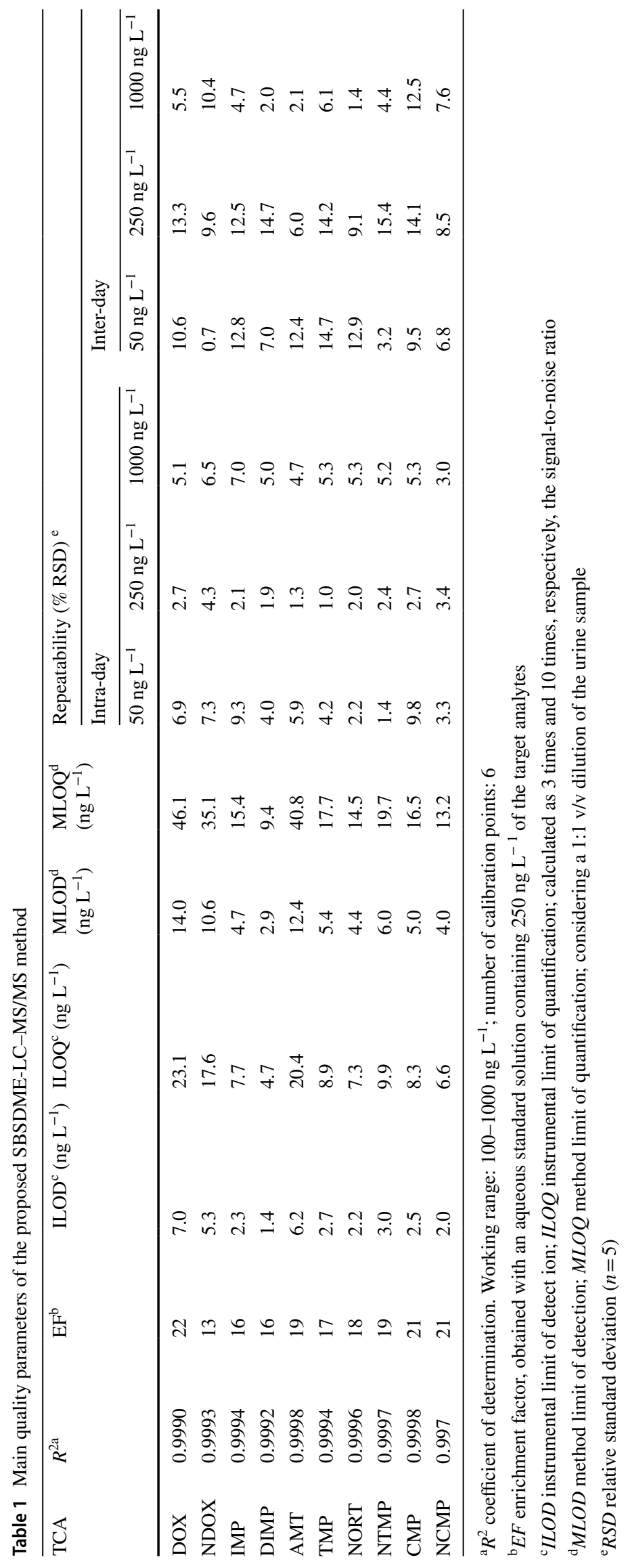


Table 2 An overview on reported nanomaterial-based methods for the determination of tricyclic antidepressants in human urine

\begin{tabular}{|c|c|c|c|c|c|c|}
\hline Analytes $^{\mathrm{a}}$ & $\begin{array}{l}\text { Microextraction } \\
\text { technique }^{b}\end{array}$ & Sorbent material $^{c}$ & Time $^{d}$ & $\begin{array}{l}\text { Instrumental } \\
\text { technique }\end{array}$ & Analytical performance ${ }^{f}$ & Ref \\
\hline $\begin{array}{l}\text { DOX, IMP, CMP, and } \\
\text { other three compounds }\end{array}$ & PMME & $\begin{array}{l}\text { Poly(MAA-co-EGDMA) } \\
\text { in combination with } \\
\text { OPA-modified Zr- } \\
\text { coated CEC }\end{array}$ & $9 \min$ & CE-UV & $\begin{array}{l}\text { EF: n.a } \\
\text { MLOD: } 3.7-8.0 \mathrm{ng} \mathrm{mL}^{-1} \\
\text { RR: } 84-107 \% \\
\text { RSD: } 0.6-9.4 \%\end{array}$ & {$[33]$} \\
\hline IMP, DIMP, CMP & SPME & $\begin{array}{l}\text { G, CTAB and PANI } \\
\text { nanocomposite }\end{array}$ & $60 \mathrm{~min}$ & TD-GC-FID & $\begin{array}{l}\text { EF: n.a } \\
\text { MLOD: } 0.10-0.35 \mathrm{ng} \mathrm{mL}^{-1} \\
\text { RR: } 94-99 \% \\
\text { RSD: } 4.8-10.4 \%\end{array}$ & {$[34]$} \\
\hline $\begin{array}{l}\text { AMT, IMP, and another } \\
\text { compound }\end{array}$ & MEPS & $\begin{array}{l}\text { PDA-Ag-PPy nanocom- } \\
\text { posite }\end{array}$ & $15 \mathrm{~min}$ & GC-MS & $\begin{array}{l}\text { EF: n.a } \\
\text { MLOD: } 0.03-0.05 \mathrm{ng} \mathrm{mL}^{-1} \\
\text { RR: } 88-104 \% \\
\text { RSD: 5-10\% }\end{array}$ & {$[35]$} \\
\hline DOX, AMT and NORT & DSPE-CAE & $\mathrm{Fe}_{3} \mathrm{O}_{4} @$ oleic acid & $19 \min$ & LC-UV & $\begin{array}{l}\text { EF: n.a } \\
: 0.5-1.4 \mathrm{ng} \mathrm{mL}{ }^{-1} \\
\text { RR: } 87-105 \% \\
\text { RSD: } 2.5-3.2 \%\end{array}$ & {$[36]$} \\
\hline $\begin{array}{l}\text { AMT, DIMP, TMP, and } \\
\text { another compound }\end{array}$ & Micro-SPE & $\begin{array}{l}\text { Poly(GMA-co-EDMA- } \\
\text { MWCNTs) }\end{array}$ & $5 \mathrm{~min}$ & LC-UV & $\begin{array}{l}\text { EF: } 24-36 \\
\text { MLOD: } 8.6-15.2 \mathrm{ng} \mathrm{mL}^{-1} \\
\text { RR: } 72-108 \% \\
\text { RSD: } 3-14 \%\end{array}$ & {$[37]$} \\
\hline AMT, IMP & MSPE & $\mathrm{Fe}_{3} \mathrm{O}_{4} @ \mathrm{TMU}-10$ & $32 \mathrm{~min}$ & LC-UV & $\begin{array}{l}\text { EF: } 48-50 \\
\text { MLOD: } 2-5 \mathrm{ng} \mathrm{mL}^{-1} \\
\text { RR: } 96-99 \% \\
\text { RSD: } 3.5-4.7 \%\end{array}$ & {$[38]$} \\
\hline AMT and NORT & MSPE & $\mathrm{Fe}_{3} \mathrm{O}_{4} @ \mathrm{SiO}_{2} @ \mathrm{~N}_{3}$ & $5 \min$ & LC-UV & $\begin{array}{l}\text { EF: n.a } \\
\text { MLOD: } 0.03-0.05 \mathrm{ng} \mathrm{mL}^{-1} \\
\text { RR: } 95-97 \% \\
\text { RSD: } 1.1-3.7 \%\end{array}$ & [39] \\
\hline DOX, AMT, NORT & SPME & $\begin{array}{l}\mathrm{POMo}_{368} / \mathrm{PANI} \text { com- } \\
\text { posite }\end{array}$ & $40 \min$ & LC-UV & $\begin{array}{l}\text { EF: } \mathrm{n} . \mathrm{a} \\
:<0.0002 \mathrm{ng} \mathrm{mL}-1 \\
\text { RR: } 92-98 \% \\
\text { RSD: } 4.1-5.9 \%\end{array}$ & {$[40]$} \\
\hline $\begin{array}{l}\text { DOX, NDOX, IMP, } \\
\text { DIMP, AMT, TMP, } \\
\text { NORT, NTMP, CMP, } \\
\text { and NCMP }\end{array}$ & SBSDME & $\begin{array}{c}\mathrm{CoFe}_{2} \mathrm{O}_{4} @ \mathrm{SiO}_{2} @ \mathrm{MPS} @ \\
\text { MAA-co-EGDMA }\end{array}$ & $10 \mathrm{~min}$ & LC-MS/MS & $\begin{array}{l}\text { EF: } 13-22 \\
\text { MLOD: } 0.0029-0.014 \mathrm{ng} \mathrm{mL}^{-1} \\
\text { RR: } 80-113 \% \\
\text { RSD: } 0.7-15.4 \%\end{array}$ & This work \\
\hline
\end{tabular}

${ }^{\text {a }} A M T$ amitriptyline; $C M P$ clomipramine; $D I M P$ desipramine; $D O X$ doxepin; IMP imipramine; $N C M P$ N-desmethylclomipramine; $N D O X$ N-desmethyldoxepin; NORT nortriptyline; NTMP N-desmethyltrimipramine; TMP trimipramine

${ }^{\mathrm{b}} C T A B$ cetyl trimethylammonium bromide; EDMA ethylene dimethacrylate; EGDMA ethylene glycol dimethacrylate; $G$ graphene; $G M A$ glycidyl methacrylate; MAA methacrylic acid; MPS 3-(trimethoxysilyl)propyl methacrylate; $M W C N T$ s multi-walled carbon nanotubes; $O P A$ octadecyl phosphonic acid; $P A N I$ polyaniline; $P D A$ polydopamine; $P O M o_{368}$ polyoxomolibdate ${ }_{368}$; $P P y$ polypyrrole

${ }^{\mathrm{c}} D S P E-C A E$ dispersive solid-phase extraction with coacervative microextraction; $M E P S$ microextraction in package syringe; $M S P E$ magnetic solid-phase extraction; $P M M E$ polymer monolith microextraction; $S B S D M E$ stir bar sorptive-dispersive microextraction; $S P E$ solid-phase extraction; SPME solid-phase microextraction

${ }^{\mathrm{d}}$ Time: extraction + desorption time

${ }^{\mathrm{e}} C E$ capillary electrophoresis; FID flame ionization detector; $G C$ gas chromatography; $L C$ liquid chromatography; $M S$ mass spectrometry; $M S /$ $M S$ tandem mass spectrometry; $T D$ thermal desorption; $U V$ ultraviolet spectrometry

${ }^{\mathrm{f}} E F$ enrichment factor; $M L O D$ method limit of detection; $n . a$. not available; $R R$ relative recovery; $R S D$ relative standard deviation

ranged from 0.7 to $15.4 \%$, showed the good precision of the proposed method.

Compared to other reported nanomaterial-based methods for the determination of TCAs in human urine (see Table 2), the proposed SBSDME approach presents different advantages. The analytical performance in terms of MLODs, even when thermal desorption was used, in addition to relative recoveries and precision, is comparable or better than previously reported methods. Furthermore, the highest number of TCAs were determined by the proposed method, 
Table 3 Relative recovery values obtained by applying the proposed SBSDME-LC-MS/ MS method

\begin{tabular}{|c|c|c|c|c|c|c|c|}
\hline \multirow[t]{2}{*}{ TCA } & \multirow{2}{*}{$\begin{array}{l}\text { Added } \\
\left(\mathrm{ng} \mathrm{mL}^{-1}\right)\end{array}$} & \multicolumn{2}{|l|}{ Volunteer A } & \multicolumn{2}{|l|}{ Volunteer B } & \multicolumn{2}{|l|}{ Volunteer C } \\
\hline & & $\begin{array}{l}\text { Found } \\
\left(\text { ng mL }^{-1}\right)\end{array}$ & $\begin{array}{l}\text { Relative } \\
\text { recovery } \\
(\%)\end{array}$ & $\begin{array}{l}\text { Found } \\
\left(\mathrm{ng} \mathrm{mL}^{-1}\right)\end{array}$ & $\begin{array}{l}\text { Relative } \\
\text { recovery } \\
(\%)\end{array}$ & $\begin{array}{l}\text { Found } \\
\left(\text { ng mL }^{-1}\right)\end{array}$ & $\begin{array}{l}\text { Relative } \\
\text { recovery } \\
(\%)\end{array}$ \\
\hline \multirow[t]{3}{*}{ DOX } & 0.00 & n.d. ${ }^{\mathrm{a}}$ & - & n.d. ${ }^{\mathrm{a}}$ & - & n.d. ${ }^{a}$ & - \\
\hline & 0.23 & $0.211 \pm 0.017$ & $91 \pm 7$ & $0.209 \pm 0.008$ & $90 \pm 4$ & $0.192 \pm 0016$ & $83 \pm 7$ \\
\hline & 0.46 & $0.464 \pm 0.012$ & $100 \pm 3$ & $0.429 \pm 0.013$ & $92 \pm 3$ & $0.463 \pm 0.005$ & $100 \pm 1$ \\
\hline \multirow[t]{3}{*}{ NDOX } & 0.00 & n.d. ${ }^{\mathrm{a}}$ & - & n.d. ${ }^{\mathrm{a}}$ & - & n.d. ${ }^{\text {a }}$ & - \\
\hline & 0.20 & $0.169 \pm 0.005$ & $84 \pm 3$ & $0.170 \pm 0.019$ & $85 \pm 9$ & $0.161 \pm 0.005$ & $81 \pm 3$ \\
\hline & 0.40 & $0.342 \pm 0.015$ & $85 \pm 4$ & $0.35 \pm 0.03$ & $87 \pm 7$ & $0.366 \pm 0.012$ & $92 \pm 3$ \\
\hline \multirow[t]{3}{*}{ IMP } & 0.00 & n.d. ${ }^{\mathrm{a}}$ & - & n.d. ${ }^{\mathrm{a}}$ & - & n.d. ${ }^{a}$ & - \\
\hline & 0.21 & $0.204 \pm 0.009$ & $103 \pm 12$ & $0.172 \pm 0.001$ & $81 \pm 1$ & $0.174 \pm 0.007$ & $82 \pm 4$ \\
\hline & 0.42 & $0.41 \pm 0.03$ & $97 \pm 7$ & $0.343 \pm 0.003$ & $81 \pm 1$ & $0.340 \pm 0.007$ & $80 \pm 2$ \\
\hline \multirow[t]{3}{*}{ DIMP } & 0.00 & n.d. ${ }^{\mathrm{a}}$ & - & n.d. ${ }^{\mathrm{a}}$ & - & n.d. ${ }^{a}$ & - \\
\hline & 0.20 & $0.210 \pm 0.005$ & $108 \pm 9$ & $0.180 \pm 0.010$ & $88 \pm 5$ & $0.168 \pm 0.015$ & $82 \pm 7$ \\
\hline & 0.41 & $0.41 \pm 0.03$ & $101 \pm 6$ & $0.340 \pm 0.017$ & $83 \pm 4$ & $0.371 \pm 0.005$ & $91 \pm 1$ \\
\hline \multirow[t]{3}{*}{ AMT } & 0.00 & n.d. ${ }^{a}$ & - & n.d. ${ }^{a}$ & - & n.d. ${ }^{a}$ & - \\
\hline & 0.21 & $0.216 \pm 0.004$ & $106 \pm 2$ & $0.167 \pm 0.008$ & $81 \pm 4$ & $0.165 \pm 0.006$ & $81 \pm 3$ \\
\hline & 0.41 & $0.420 \pm 0.005$ & $102 \pm 1$ & $0.329 \pm 0.008$ & $80 \pm 2$ & $0.348 \pm 0.001$ & $85 \pm 1$ \\
\hline \multirow[t]{3}{*}{ TMP } & 0.00 & n.d. ${ }^{\mathrm{a}}$ & - & n.d. ${ }^{\mathrm{a}}$ & - & n.d. ${ }^{a}$ & - \\
\hline & 0.21 & $0.23 \pm 0.02$ & $107 \pm 11$ & $0.192 \pm 0.009$ & $91 \pm 4$ & $0.176 \pm 0.011$ & $83 \pm 5$ \\
\hline & 0.42 & $0.437 \pm 0.018$ & $103 \pm 4$ & $0.373 \pm 0.013$ & $88 \pm 3$ & $0.392 \pm 0.002$ & $92 \pm 1$ \\
\hline \multirow[t]{3}{*}{ NORT } & 0.00 & n.d. ${ }^{\mathrm{a}}$ & - & n.d. ${ }^{\mathrm{a}}$ & - & n.d. $^{a}$ & - \\
\hline & 0.20 & $0.200 \pm 0.018$ & $92 \pm 4$ & $0.180 \pm 0.011$ & $92 \pm 6$ & $0.163 \pm 0.011$ & $83 \pm 5$ \\
\hline & 0.39 & $0.394 \pm 0.010$ & $100 \pm$ & $0.338 \pm 0.013$ & $86 \pm 3$ & $0.360 \pm 0.003$ & $92 \pm 1$ \\
\hline \multirow[t]{3}{*}{ NTMP } & 0.00 & n.d. ${ }^{a}$ & - & n.d. ${ }^{\mathrm{a}}$ & - & n.d. ${ }^{a}$ & - \\
\hline & 0.20 & $0.188 \pm 0.015$ & $94 \pm 8$ & $0.161 \pm 0.009$ & $80 \pm 5$ & $0.160 \pm 0.004$ & $83 \pm 5$ \\
\hline & 0.40 & $0.38 \pm 0.02$ & $95 \pm 5$ & $0.320 \pm 0.023$ & $80 \pm 6$ & $0.328 \pm 0.001$ & $92 \pm 1$ \\
\hline \multirow[t]{3}{*}{ CMP } & 0.00 & $0.11 \pm 0.01$ & - & n.d. ${ }^{\mathrm{a}}$ & - & n.d. ${ }^{a}$ & - \\
\hline & 0.21 & $0.32 \pm 0.05$ & $113 \pm 6$ & $0.185 \pm 0.013$ & $89 \pm 7$ & $0.169 \pm 0.002$ & $81 \pm 1$ \\
\hline & 0.42 & $0.538 \pm 0.009$ & $101 \pm 2$ & $0.353 \pm 0.014$ & $84 \pm 3$ & $0.404 \pm 0.008$ & $96 \pm 2$ \\
\hline \multirow[t]{3}{*}{ NCMP } & 0.00 & $0.66 \pm 0.04$ & - & n.d. ${ }^{\mathrm{a}}$ & - & n.d. ${ }^{a}$ & - \\
\hline & 0.20 & $0.87 \pm 0.03$ & $102 \pm 13$ & $0.179 \pm 0.020$ & $89 \pm 10$ & $0.167 \pm 0.013$ & $83 \pm 7$ \\
\hline & 0.40 & $1.071 \pm 0.016$ & $102 \pm 4$ & $0.336 \pm 0.018$ & $84 \pm 5$ & $0.382 \pm 0.001$ & $96 \pm 1$ \\
\hline
\end{tabular}

${ }^{\mathrm{a}}$ n.d. not detected including their main metabolites in urine. The overall extraction plus desorption time is similar to other dynamic extraction techniques whereas, as expected, is shorter when compared to static ones. Moreover, no additional equipment except a stirring plate and a bar-shaped magnet is needed to perform the extraction and rapid retrieval of the material, thus avoiding centrifugation steps making it fast and easy to handle.

On the other hand, the main drawback of the proposed method is the step-by-step synthesis procedure of the sorbent material, not being able to synthesize it in a single step. However, the proposed synthesis procedure allows to obtain large amounts of sorbent $(>1.5 \mathrm{~g})$, and considering the small amount of material that was used in each extraction (i.e.,
$15 \mathrm{mg}$ ), it allows to carry out many extractions in just a single synthesis. In addition, as the polymer is chemically coating MNPs, rather than having the MNPs physically embedded into it, the contact area between analytes and sorbent is increased due to nanometric size and, moreover, leaching problems are minimized.

\section{Application to the analysis of real human urine samples}

The proposed SBSDME method was applied to the analysis of the five target TCAs and their main metabolites in three real human urine samples in order to evaluate its 
accuracy and analytical utility. In this sense, the proposed method was applied to one urine sample from a volunteer (Volunteer A) consuming a prescribed drug, which contained $25 \mathrm{mg}$ of CMP per tablet, three times per day, and two urine samples from two healthy volunteers (Volunteers B and C) who did not take any TCA. As expected, only the urine belonging to Volunteer A contained CMP and its main metabolite (NCMP). Thus, $0.28 \pm 0.03$ and $1.64 \pm 0.10 \mu \mathrm{g} \mathrm{mg}^{-1}$ of creatinine for CMP and NCMP, respectively, were found.

Regarding the accuracy of the proposed method (Table 3), these three samples were spiked at two concentration levels (i.e., 200 and $400 \mathrm{ng} \mathrm{L}^{-1}$ ) of the target analytes, showing good relative recovery values $(80-113 \%)$. Therefore, the external calibration approach works in a reliable way.

\section{Conclusions}

In the present work, an optimized SBSDME method that contributes to the development of sensitive methods for the determination of five TCAs and their main metabolites in urine samples has been presented. The use of $\mathrm{CoFe}_{2} \mathrm{O}_{4} @$ $\mathrm{SiO}_{2} @$ MPS@MAA-co-EGDMA as sorbent phase provides good extraction of the proposed TCAs, through both hydrophobic and electrostatic interactions. This is the first time that this interesting polymer has been used in the SBSDME approach and also for the determination of these compounds. Moreover, due to the features of this polymer, the proposed magnetic sorbent may be used in new applications to extract many other families of basic compounds containing, for instance, amino functional groups. The proposed SBSDME method has been validated in terms of linearity, enrichment factor, LODs and LOQs, repeatability, and accuracy, obtaining good results.

This work expands the analytical potential of SBSDME to other analytes and to the use of new sorbent phases in this technique, demonstrating its versatility regardless the chemical nature of the analytes.

Supplementary Information The online version contains supplementary material available at https://doi.org/10.1007/s00604-021-05156-7.

Acknowledgements The authors are very grateful to Dr. Antonio Martín-Esteban for the interesting discussions about the properties of MAA-co-EGDMA polymers.

Author contribution Víctor Vállez-Gomis: data curation; formal analysis; investigation; methodology; validation; writing - original draft. Sara Exojo-Trujillo: data curation; formal analysis; investigation; methodology. Juan L. Benedé: methodology; visualization; writing review - editing. Alberto Chisvert: funding acquisition; investigation; methodology; project administration; resources; supervision; writing review - editing. Amparo Salvador: funding acquisition; investigation; methodology; project administration; resources; supervision; writing - review - editing.

Funding Open Access funding provided thanks to the CRUE-CSIC agreement with Springer Nature. Grant PID2020-118924RB-I00 funded by MCIN/AEI/ 10.13039/501100011033 is greatly appreciated. V.V.-G and J.L.B. received from the Generalitat Valenciana and the European Social Fund the predoctoral and postdoctoral grants, respectively. This article is based upon work from the National Thematic Network on Sample Treatment (RED-2018-102522-T) of the Spanish Ministry of Science, Innovation and Universities, and the Sample Preparation Study Group and Network supported by the Division of Analytical Chemistry of the European Chemical Society.

\section{Declarations}

Conflict of interest The authors declare no competing interests.

Open Access This article is licensed under a Creative Commons Attribution 4.0 International License, which permits use, sharing, adaptation, distribution and reproduction in any medium or format, as long as you give appropriate credit to the original author(s) and the source, provide a link to the Creative Commons licence, and indicate if changes were made. The images or other third party material in this article are included in the article's Creative Commons licence, unless indicated otherwise in a credit line to the material. If material is not included in the article's Creative Commons licence and your intended use is not permitted by statutory regulation or exceeds the permitted use, you will need to obtain permission directly from the copyright holder. To view a copy of this licence, visit http://creativecommons.org/licenses/by/4.0/.

\section{References}

1. Moraczewski J, Aedma KK (2021) Tricyclic antidepressants. In: StatPearls [Internet]. Treasure Island (FL): StatPearls Publishing

2. Taylor D, Lenox-Smith A, Bradley A (2013) A review of the suitability of duloxetine and venlafaxine for use in patients with depression in primary care with a focus on cardiovascular safety, suicide and mortality due to antidepressant overdose. Ther Adv Psychopharmacol 3:151-161. https://doi.org/10.1177/ 2045125312472890

3. Farag RS, Darwish MZ, Fathy WM, Hammad HA (2013) New HPLC method to detect amitriptyline in the blood of rats on combination treatment. Int J Chem Anal Sci 4:120-124. https:// doi.org/10.1016/j.ijcas.2013.06.001

4. Patel NP, Sanyal M, Sharma N et al (2018) Highly sensitive LC-MS/MS method to estimate doxepin and its metabolite nordoxepin in human plasma for a bioequivalence study. J Pharm Anal 8:378-385. https://doi.org/10.1016/j.jpha.2017.06.004

5. Degreef M, van Nuijs ALN, Maudens KE (2018) Validation of a simple, fast liquid chromatography-tandem mass spectrometry method for the simultaneous quantification of 40 antidepressant drugs or their metabolites in plasma. Clin Chim Acta 485:243257. https://doi.org/10.1016/j.cca.2018.06.047

6. Chambers EE, Woodcock MJ, Wheaton JP et al (2014) Systematic development of an UPLC-MS/MS method for the determination of tricyclic antidepressants in human urine. J Pharm Biomed Anal 88:660-665. https://doi.org/10.1016/j.jpba.2013. 09.001

7. Shin SS, Borg D, Stripp R (2020) Developing and validating a fast and accurate method to quantify 18 antidepressants in oral fluid 
samples using SPE and LC-MS-MS. J Anal Toxicol 44:610-617. https://doi.org/10.1093/JAT/BKZ117

8. Uddin MN, Samanidou VF, Papadoyannis IN (2008) Development and validation of an HPLC method for the determination of benzodiazepines and tricyclic antidepressants in biological fluids after sequential SPE. J Sep Sci 31:2358-2370. https://doi.org/10. $1002 /$ jssc. 200800079

9. Sempio C, Morini L, Vignali C, Groppi A (2014) Simple and sensitive screening and quantitative determination of 88 psychoactive drugs and their metabolites in blood through LC-MS/MS: application on postmortem samples. J Chromatogr B Anal Technol Biomed Life Sci 970:1-7. https://doi.org/10.1016/j.jchromb. 2014.08.039

10. Lin CN, Juenke JM, Johnson-Davis KL (2014) Method validation of a tricyclic antidepressant drug panel in urine by UPLC-MS/MS. Ann Clin Lab Sci 44:431-436

11. Zhao J, Shin Y, Chun KH et al (2016) A simple, rapid and Reliable method to determine imipramine and desipramine in mouse serum using ultra-high-performance liquid chromatography-quadrupoletime-of-flight mass spectrometry. J Chromatogr Sci 54:561-568. https://doi.org/10.1093/chromsci/bmv187

12. Soares S, Barroso M, Gallardo E (2020) A review of current bioanalytical approaches in sample pretreatment techniques for the determination of antidepressants in biological specimens. Rev Anal Chem 40:12-32. https://doi.org/10.1515/revac-2021-0124

13. Manousi N, Samanidou VF (2019) Recent advances in the HPLC analysis of tricyclic antidepressants in bio-samples. Mini-Reviews Med Chem 20:24-38. https://doi.org/10.2174/138955751966619 0617150518

14. Chisvert A, Cárdenas S, Lucena R (2019) Dispersive micro-solid phase extraction. TrAC - Trends Anal Chem 112:226-233. https:// doi.org/10.1016/j.trac.2018.12.005

15. Di S, Ning T, Yu J et al (2020) Recent advances and applications of magnetic nanomaterials in environmental sample analysis. TrAC - Trends Anal Chem 126:115864. https://doi.org/10.1016/j. trac. 2020.115864

16. Li XS, Zhu GT, Luo YB et al (2013) Synthesis and applications of functionalized magnetic materials in sample preparation. TrAC - Trends Anal Chem 45:233-247. https://doi.org/10.1016/j.trac. 2012.10.015

17. Vállez-Gomis V, Grau J, Benedé JL et al (2021) Fundamentals and applications of stir bar sorptive dispersive microextraction: a tutorial review. Anal Chim Acta 1153:338271. https://doi.org/10. 1016/j.aca.2021.338271

18. Benedé JL, Chisvert A, Giokas DL, Salvador A (2014) Development of stir bar sorptive-dispersive microextraction mediated by magnetic nanoparticles and its analytical application to the determination of hydrophobic organic compounds in aqueous media. J Chromatogr A 1362:25-33. https://doi.org/10.1016/j.chroma. 2014.08.024

19. Azzouz A, Kailasa SK, Lee SS et al (2018) Review of nanomaterials as sorbents in solid-phase extraction for environmental samples. Trends Anal Chem 108:347-369. https://doi.org/10.1016/j. trac.2018.08.009

20. Fadillah G, Saputra OA, Saleh TA (2020) Trends in polymers functionalized nanostructures for analysis of environmental pollutants. Trends Environ Anal Chem 26: https://doi.org/10.1016/j. teac.2020.e00084

21. Ghorbani M, Aghamohammadhassan M, Ghorbani H, Zabihi A (2020) Trends in sorbent development for dispersive micro-solid phase extraction. Microchem J 158:105250. https://doi.org/10. 1016/j.microc.2020.105250

22. Nischang I, Causon TJ (2016) Porous polymer monoliths: from their fundamental structure to analytical engineering applications. TrAC - Trends Anal Chem 75:108-117. https://doi.org/10.1016/j. trac.2015.05.013
23. Su R, Zhao X, Li Z et al (2010) Poly(methacrylic acid-co-ethylene glycol dimethacrylate) monolith microextraction coupled with high performance liquid chromatography for the determination of phthalate esters in cosmetics. Anal Chim Acta 676:103-108. https://doi.org/10.1016/j.aca.2010.07.039

24. Sorribes-Soriano A, Valencia A, Esteve-Turrillas FA et al (2019) Development of pipette tip-based poly(methacrylic acid-co-ethylene glycol dimethacrylate) monolith for the extraction of drugs of abuse from oral fluid samples. Talanta 205:120158. https://doi. org/10.1016/j.talanta.2019.120158

25. Arias PG, Martínez-Pérez-Cejuela H, Combès A et al (2020) Selective solid-phase extraction of organophosphorus pesticides and their oxon-derivatives from water samples using molecularly imprinted polymer followed by high-performance liquid chromatography with UV detection. J Chromatogr A 1626:461346. https://doi.org/10.1016/j.chroma.2020.461346

26. Fan Y, Feng YQ, Da SL, Shi ZG (2004) Poly (methacrylic acidethylene glycol dimethacrylate) monolithic capillary for in-tube solid phase microextraction coupled to high performance liquid chromatography and its application to determination of basic drugs in human serum. Anal Chim Acta 523:251-258. https:// doi.org/10.1016/j.aca.2004.07.052

27. Li Y, Li W, Wang Y et al (2013) Development of a solid-phase microextraction fiber coated with poly(methacrylic acid-ethylene glycol dimethacrylate) and its application for the determination of chlorophenols in water coupled with GC. J Sep Sci 36:2121-2127. https://doi.org/10.1002/jssc.201200979

28. Gao Q, Luo D, Ding J, Feng YQ (2010) Rapid magnetic solidphase extraction based on magnetite/silica/poly(methacrylic acidco-ethylene glycol dimethacrylate) composite microspheres for the determination of sulfonamide in milk samples. J Chromatogr A 1217:5602-5609. https://doi.org/10.1016/j.chroma.2010.06.067

29. Maaz K, Mumtaz A, Hasanain SK, Ceylan A (2007) Synthesis and magnetic properties of cobalt ferrite $\left(\mathrm{CoFe}_{2} \mathrm{O}_{4}\right)$ nanoparticles prepared by wet chemical route. J Magn Magn Mater 308:289-295. https://doi.org/10.1016/j.jmmm.2006.06.003

30. Zhang Z, Niu D, Li Y, Shi J (2018) Magnetic, core-shell structured and surface molecularly imprinted polymers for the rapid and selective recognition of salicylic acid from aqueous solutions. Appl Surf Sci 435:178-186. https://doi.org/10.1016/j.apsusc. 2017.11.033

31. Bezerra MA, Santelli RE, Oliveira EP et al (2008) Response surface methodology (RSM) as a tool for optimization in analytical chemistry. Talanta 76:965-977. https://doi.org/10.1016/j.talanta. 2008.05.019

32. Andrade JM, Estévez-Pérez MG (2014) Statistical comparison of the slopes of two regression lines: a tutorial. Anal Chim Acta 838:1-12. https://doi.org/10.1016/j.aca.2014.04.057

33. Wei F, Fan J, Zheng MM, Feng YQ (2010) Combining poly (methacrylic acid-coethylene glycol dimethacrylate) monolith microextraction and octadecyl phosphonic acid-modified zirconia-coated CEC with field-enhanced sample injection for analysis of antidepressants in human plasma and urine. Electrophoresis 31:714-723. https://doi.org/10.1002/elps.200900425

34. Abedi H, Ebrahimzadeh H, Ghasemi JB (2015) Solid phase headspace microextraction of tricyclic antidepressants using a directly prepared nanocomposite consisting of graphene, CTAB and polyaniline. Microchim Acta 182:633-641. https://doi.org/10.1007/ s00604-014-1367-6

35. Bagheri H, Banihashemi S, Zandian FK (2016) Microextraction of antidepressant drugs into syringes packed with a nanocomposite consisting of polydopamine, silver nanoparticles and polypyrrole. Microchim Acta 183:195-202. https://doi.org/10.1007/ s00604-015-1606-5

36. Jannesar R, Zare F, Ghaedi M, Daneshfar A (2016) Dispersion of hydrophobic magnetic nanoparticles using ultarsonic-assisted in 
combination with coacervative microextraction for the simultaneous preconcentration and determination of tricyclic antidepressant drugs in biological fluids. Ultrason Sonochem 32:380-386. https://doi.org/10.1016/j.ultsonch.2016.04.010

37. Fresco-Cala B, Mompó-Roselló Ó, Simó-Alfonso EF et al (2018) Carbon nanotube-modified monolithic polymethacrylate pipette tips for (micro)solid-phase extraction of antidepressants from urine samples. Microchim Acta 185:127. https://doi.org/10.1007/ s00604-017-2659-4

38. Safari M, Shahlaei M, Yamini Y et al (2018) Magnetic framework composite as sorbent for magnetic solid phase extraction coupled with high performance liquid chromatography for simultaneous extraction and determination of tricyclic antidepressants. Anal Chim Acta 1034:204-213. https://doi.org/10.1016/j.aca.2018.06. 023
39. Fahimirad B, Rajabi M, Elhampour A (2019) A rapid and simple extraction of anti-depressant drugs by effervescent salt-assisted dispersive magnetic micro solid-phase extraction method using new adsorbent $\mathrm{Fe}_{3} \mathrm{O}_{4} @ \mathrm{SiO}_{2} @ \mathrm{~N}_{3}$. Anal Chim Acta 1047:275-284. https://doi.org/10.1016/j.aca.2018.10.028

40. Amoli HS, Yamini Y, Darmani H (2020) Polyoxomolybdate ${ }_{368} /$ polyaniline nanocomposite as a novel fiber for solid-phase microextraction of antidepressant drugs in biological samples. J Sep Sci 43:2636-2645. https://doi.org/10.1002/jssc.201901152

Publisher's note Springer Nature remains neutral with regard to jurisdictional claims in published maps and institutional affiliations. 